\title{
CLINICAL EXPECTATIONS: WHAT FACILITATORS EXPECT FROM ESL STUDENTS ON CLINICAL PLACEMENT.
}

\begin{abstract}
Many nursing students for whom English is a second language (ESL) face challenges related to communication on clinical placement and although clinical facilitators are not usually trained language assessors, they are often in a position of needing to assess ESL students' clinical language performance. Little is known, however, about the particular areas of clinical performance facilitators focus on when they are assessing ESL students. This paper discusses the results of a study of facilitators' written assessment comments about the clinical performance of a small group of ESL nursing students over a two and a half year period. These comments were documented on students' clinical assessment forms at the end of each placement. The results provide a more detailed insight into facilitators' expectations of students' language performance and the particular challenges faced by ESL students and indicate that facilitators have clear expectations of ESL students regarding communication, learning styles and professional demeanour. These findings may be useful in preparing ESL students for clinical placement, by making explicit the behaviours facilitators value and may contribute to the professional development of clinical facilitators by exploring some of the complexities in assessing ESL students.
\end{abstract}

Key words [3 or 4] English as a second language; communication; nursing students; clinical placement

\section{INTRODUCTION}

Increasing numbers of students from culturally and linguistically diverse backgrounds is a positive step towards creating a health care workforce which better reflects the multiplicity of patient populations in many countries, such as Australia, Canada, the United States of America and the United Kingdom (Choi 2005; Gilchrist \& Rector 2007). However, before graduating into the nursing workforce, students must succeed in their undergraduate degree. Internationally, there are indications that some ESL students, particularly if recently arrived in the country of study, face difficulties on clinical placement due to language and cultural differences (Guhde 2003; San Miguel et al. 2006). The nursing profession requires high levels of language from students as they need to readily chat with patients, family and staff to build rapport, which entails familiarity with everyday language including slang, and also carry out the business of nursing, communicating health information using professional terminology (Malthus et al 2005). Globally, many universities are beginning to recognise these difficulties and establish programmes that provide students with explicit instruction in some of the sociocultural and linguistic expectations of clinical practice (Bosher \& Smalkoski 2002; 
Boughton et al 2010; Gunn-Lewis \& Smith 1999; Hussin 1999; Malthus et al 2005; Seibold et al 2007). Such programmes are usually informed by educators' retrospective reflections on their experiences with ESL (San Miguel et al. 2006) or minority students (Brown 2008) and, in particular, the types of difficulties educators think students usually face on clinical. Little is known about what educators actually focus on when supervising and assessing students in the clinical setting.

Students are usually assessed on clinical practice by nurse educators, called clinical facilitators in Australia and mentors or practice teachers in the UK. In this paper the term facilitators is used to describe an educator who teaches and assesses students on clinical placement. Although many facilitators do not have ESL training, they need to assess students' language ability as communication or interpersonal skills is a core nursing competency (Australian Nursing and Midwifery Council 2006; Nursing and Midwifery Council 2010). Whilst facilitators, as nursing professionals, may be the most suitable people to assess students' language ability (Chur-Hansen \&Vernon-Roberts 1998), little is known about how they do this and what aspects of communication they focus on in determining whether students pass their clinical placement.

The purpose of this paper is to discuss the expectations that facilitators have when assessing ESL students' clinical communication abilities. These expectations were identified by investigating the written comments documented by clinical facilitators on the clinical assessment forms of a small group of ESL students' over a two and a half year period. These assessment forms are completed by facilitators during each clinical placement and used to determine whether students pass the placement. The study, carried out at a large urban Australian university, analysed all facilitator comments made about the 'non clinical skills' performance of students, including communication, learning style and professional demeanour. The findings provide valuable insights into expectations of students and particular challenges faced by ESL students during clinical placement.

\section{LITERATURE REVIEW}

Clinical placement is an essential component of nursing education, ensuring students become safe practitioners and are socialised into the nursing profession (Melia 1987). In assessing students on clinical placement, many assessors focus on the practical skills students require (McCarthy \& Murphy 2008). However, assessment tools described in the literature often refer to other abilities including effective communication, self directed learning and professional demeanour (Fothergill Bourbonnais et al 2008).

Communication and learning styles have been highlighted as being particularly problematic for some ESL students (Rogan et al 2006). In particular, students may experience difficulty in understanding colloquial language (Gonda et al 1995) and staff instructions (Bosher \& Smalkowski 2002); making small talk, giving instructions and explanations to patients (San Miguel et al 2006); and using professional language (Malu \& Figlear 1998).

Little research in nursing focuses on assessment of students' communication or interpersonal skills. However, one study in the USA (Jette et al 2007) that focused on 
physical therapy (elsewhere know as physiotherapy) students offers some insights into educators' expectations of students on clinical placement regarding non-clinical skills such as interpersonal skills. The study investigated the assessment of graduating students to determine how educators made judgements about students' performance. The assessment model developed from this study highlights the importance of the non-clinical skills in the practice setting. Jette et al. (2007, p. 840) argue that 'interpersonal communication and professional demeanour supersede knowledge, clinical skills and clinical decision making' because 'students needed to be polite, confident, respectful, and able to get along with all sorts of people in order for them to be able to effectively demonstrate their knowledge and skills to patients, CIs [clinical instructors] and other team members'. The most important theme in the model is self directed learning because, in demonstrating clinical skills, safety, interpersonal skills and professional demeanour, physical therapists had to be able to evaluate their performance and ask for help or get more information when they needed it. They also needed to be willing to accept criticism, learn from it and change. These comments seem equally relevant to nursing and indicate the potential challenges for ESL students needing to develop the language and cultural knowledge to perform successfully in these areas.

Interpersonal communication, professional demeanour and learning styles are culturally bound and given the cultural and linguistic diversity of many workplaces, what constitutes a 'good' and 'successful' student may not also be a shared view amongst students and staff. It may be that facilitators' assessments are, at times, based on students' cultural behaviour rather than language performance. In a study of written comments made on medical students' clinical performance, Chur-Hansen \& VernonRoberts (1998 p. 355) suggest that 'perhaps Asian students are regarded as having 'language problems' because they are not vocal and do not question their teachers, when in fact they are obeying cultural rules of respect'. Given that most facilitators are not trained in assessing language, Chur-Hansen \& Vernon-Roberts (1998, p. 354) propose that clinical educators may 'make unsubstantiated judgements based upon fragmentary information, or upon factors not necessarily related to English language proficiency, such as personality or appearance'.

The notion of subjectivity in assessing students (not just ESL) on clinical placement has been raised in nursing literature (Dolan 2003). Assessment tools can be open to bias and influenced by how well students adapt to the clinical environment (Calman et al 2002). Indeed, Jette et al. (2007) found that although educators in their study focused on particular attributes, such as interpersonal, communication and professional demeanour, they used these observations to make an overall intuitive decision. The authors raise a problem with this use of intuition, arguing that educators may evaluate students according to their own beliefs about which particular student attributes are representative of 'good' students. If educators, for example, think good students are outgoing then they will probably evaluate outgoing students highly even if they lack clinical skills. Of course, the desirability of particular student qualities is also influenced by culturally accepted ways of behaving which can lead to misunderstandings if these norms remain unspoken and unnegotiated. 
Written assessment comments are the only formal documentation of what happens on clinical placement. They may indicate more widely held undocumented views of facilitators as facilitators may be more cautious about documenting negative feedback than presenting that feedback verbally (Chur-Hansen \& Vernon-Roberts 1998; Clynes \& Raftery 2008) because it is a permanent record. Assessors in Clynes \&Raftery's, (2008) study tended to give negative feedback verbally but dilute it in writing with the assumption that readers would 'read between the lines' (p. 32). They found that negative feedback relating to non-clinical skills was particularly problematic because assessors were concerned that students might interpret feedback as a comment on them as a person rather than on their performance.

There are few studies that investigate clinical facilitators' written comments about students to identify the abilities they assess (rather than abilities they say they assess, when asked at a later date) and the types of comments they make about communication, learning style and professional demeanour. The only study involving ESL students in a health related discipline analysed comments made by clinical teachers about a large group of medical students' English language proficiency (Chur-Hansen \& VernonRoberts 1998) and found relatively few comments about students' language performance, the most frequent of which were about general language ability. The study reported in this paper focuses specifically on facilitators' expectations of ESL nursing students' performance in terms of communication, learning style and professional demeanour during clinical placement.

\section{METHOD}

Students previously involved in a pilot study of a clinical language support program for ESL nursing students, called Clinically Speaking, were invited to participate in the study. The pilot study evaluated the short-term effects of a language programme aimed at students identified during their first clinical placement as needing to improve their clinical communication skills (Rogan et al 2006; San Miguel et al 2006). All students involved in the pilot study were invited to participate and ten of twelve students agreed.

Facilitators' comments on all clinical assessment forms for each of the ten students were examined, from the second semester of first year to the final semester of their degree (a two and a half year period). In the first year only, facilitators were required to comment on specific students abilities such as 'can introduce self to patient'. The first year assessment form had been redesigned as part of the communication programme, Clinically Speaking, to give facilitators more guidance in referring students in need of communication development to the programme (see San Miguel et al 2006 for more details of this procedure). For second and third year students no specific guidelines were provided on the assessment forms as to what specific areas facilitators might comment on regarding strengths and improvements.

The study used a descriptive interpretive design (Thorne et al 1997). Comments not directly related to students' clinical skills were documented and formed a composite bank of remarks made by facilitators over two and a half years. The comments were made by different assessors in a number of clinical settings about different students. A thematic 
analysis of the bank of comments was carried out by one of the researchers. Key themes were identified and synthesised into two major categories. The second researcher checked and confirmed initial themes and categories and, where differences arose, both researchers analysed and reanalysed data until agreement on themes was reached.

Ethics permission for this study was granted by the university ethics committee.

\section{RESULTS}

Facilitators' comments are represented in two main categories: the first is 'good' students who were a 'pleasure to work with' and the second, 'improvements required', encapsulating what facilitators wanted students to do to improve their clinical performance. Each category has the same three themes, that is, communication, learning style and bedside manner. The 'good' students category had one extra theme, personality factors. These themes are described in more detail below.

Good' students describe those who communicate well with patients and staff, have a good bedside manner, show a willingness to learn and are self-directed learners. There were also a number of comments associated with 'good' students personalities such as 'enthusiastic' and 'outgoing'. In contrast, the category 'improvements required' describes students who need to improve communication with patients and staff, be assertive and proactive, be engaged in the learning experience and take responsibility for their own learning.

\section{Communication}

A major theme in both categories relates to students' ability to communicate with patients and staff, with most comments focusing on students' communication with patients. In the 'good' students category, language was not commented on as problematic as students were able to communicate in appropriate and effective ways. However, in the 'improvements required' category, language was seen as impeding appropriate and effective communication.

Many of the positive comments in the 'good' students category related generally to communication and English speaking ability, such as communicates effectively with patients and staff. However, many comments also related to specific aspects of communication. Facilitators noted aspects of nurse patient communication that students were able to do, such as: introducing themselves to patients; making small talk; gaining consent before undertaking procedures; giving and gathering health information; checking they had understood patients and staff; communicating in appropriate ways to specific groups (e.g. elderly and disabled); and completing written documentation appropriately. 
In the 'improvements required' category, many comments referred generally to the need to improve English and communication skills, for example more improvement with English skills; needs to further enhance his communication skills i.e. improvement is needed in grammar, sentence structure, spelling and some terminology. However, many comments also referred to specific aspects of language that hindered students' communication ability. Problems raised were pronunciation, for example, not speaking clearly; patients have difficulty understanding; slow speech down and the use of non verbal communication, for example, does not use attending behaviours especially eye contact to show listening; can be more observant and pick up non verbal cues from patients and staff. Other problems raised referred to specific contexts where students had difficulties communicating. These contexts included: giving and gathering health information, for example, at times is inappropriate especially explaining to her patients the care she was about to deliver; making small talk; introducing themselves to patients; communicating with particular patient groups; and checking they had understood staff. Two other problematic aspects of communication noted were the use of terminology, use more medical terminology; need to understand more abbreviations, and written English, needs to develop written English skills further; written English practice in progress notes, care plans.

A good bedside manner

Another major theme in both categories is a good bedside manner. This theme illustrates the qualities that facilitators expected students to demonstrate in their relationships with patients. These qualities included being caring and empathetic, for example, gentle and compassionate; establishing rapport, for example, easily getting good relationship with patients; being polite, courteous and respectful; maintaining patients' dignity and confidentiality; and being pleasant, cheerful friendly and polite. Those students requiring improvements were told in written comments that they needed to take time to get to know your patient; increase personal confidence in conversing with clients and thinking of conversation topics; and use attending behaviours especially eye contact to show listening.

\section{Learning style}

A third major theme relates to students' learning, including students' willingness to learn and learning style. In particular, facilitators seemed to value students who were selfdirected learners, showed initiative and asked questions to develop their professional knowledge and clarify their understanding. Signs of a willingness to learn included being hard working and seeking out opportunities to learn, being inquisitive and interested in the clinical setting. Comments which illustrate this willingness include: has been a wonderful student. A pleasure to teach, a 'sponge' for learning; willingness to achieve and learn; interested and open to new experience; and wanted to work hard to ensure she has made the most of this opportunity. Likewise, accepting criticism was seen as a sign of being willing to learn, ability to take learning criticism and accepts feedback in a positive manner. The desire of facilitators for a self-directed learning style is underscored by the improvements they suggested to those students who did not 
demonstrate this willingness and inquisitiveness about learning. Facilitators suggested these students needed to ask more question; become a little more assertive; and be more vocal. There is a perception that without these behaviours, students were showing an intermittent reluctance to engage in [the] learning experience.

\section{Personality Factors}

The theme 'personality factors' only exists in the 'good' students category. These descriptions seem to be an overall assessment of students' personalities compared to comments about personal qualities in terms of a bedside manner, for example, Cherry is an absolute pleasure to work with ...works extremely well with all staff - will make a great $R N$. What is commented on positively was being happy, enthusiastic and outgoing. Such students showed bubbling enthusiasm, happiness. There was also the perception that being outgoing resulted in a better communicator as illustrated in the following comment: has been more outgoing this semester therefore more effective communicator; pleasant and cheerful; Such personality factors were not mentioned in the 'improvements required' category. No student was told to be more enthusiastic or more pleasant.

\section{DISCUSSION}

This study provides insight into facilitators' expectations of ESL students' clinical practice through a study of their written assessment comments about students' clinical behaviour. Results indicate that facilitators expected students to communicate well with patients and staff, have a 'good' bedside manner, and be proactive and assertive, engaged in the learning experience and self-directed learners. It also seems that, at times, facilitators focused on students' personalities rather than clinical behaviours, using their intuition to make overall judgements about students.

Facilitators expected students to communicate clearly and indeed many specified the nature of clear communication. Unlike Chur- Hansen and Vernon-Robert's (1998) study, in which comments related to general language, in this study facilitators commented on specific aspects of communication such as introductions, small talk, instructions and explanations, non-verbal communication and pronunciation, indicating the importance of both relational and transactional aspects of communication (Malthus et al 2005), that is the ability to build rapport with patients and staff (relational) and carry out the business of nursing such as relating health information, using professional terminology and asking for consent (transactional). Facilitators also expected clear written communication, an aspect somewhat neglected in the literature where the focus is either on spoken communication on clinical practice (Bosher \& Smalkowski 2002; Gonda et al 1995; San Miguel et al 2006) or problems faced in the academic environment (Omeri et al 2003)), rather than written workplace communication such as progress reports and notes. These documents are an essential component of patient care and may be problematic for some ESL students. There is a need for further research into the linguistic demands of writing for the workplace, the challenges these demands may pose for ESL students and strategies for addressing these challenges. 
In this study, the prevalence of specific comments related to communication may have resulted from the detailed student clinical assessment form. The form specifies the types of communication expected of students at different stages of their degree, for example, for first year students, 'introduce themselves appropriately to patients' 'begin to make small talk'. At the time of the study, the form had been developed in detail for first year students only. However, facilitators who had worked with first year students may have been influenced by the specific nature of the first year assessment form. This specificity may address Chur-Hansen and Vernon's (1998) concern regarding the potential for educators to assess students' use of language based on factors not necessarily related to English language proficiency, such as personality. This could be averted by clearly specifying what kind of communication students should be confident with at each stage of their degree.

Some of the themes in this study overlap. It seemed difficult to comment on good bedside manner without including communication as building rapport relies on verbal as well as non-verbal communication. A good bedside manner also included comments such as being courteous, polite and respectful. These qualities align to Jette et al's (2007) attribute of professional demeanour and are important not only in establishing rapport with patients, but also in building effective relationships with Registered Nurses and assessors, a factor linked to positive clinical experiences for students (Brammer 2006; San Miguel \& Rogan 2009). However, professional demeanour can also be culturally bound. Being respectful in one culture, for example, may entail making eye contact. In other cultural contexts, it may be equally respectful not to make eye contact. Cultural norms need to be discussed with students and facilitators to clarify misunderstandings so that students are aware of possible effects of their behaviour on clinical placement and assessors are aware of potential misunderstandings related to cultural expectations.

The influence of students' learning style on facilitators' judgements is clear from this study. Facilitators wanted assertive, confident students who asked questions and like the educators in Jette et al's (2007) study, expected students to take criticisms well.

However, certain factors may make it difficult for students to adopt the facilitators' preferred style, a style that not only requires confidence with spoken language but confidence to also question RNs and facilitators who are in authoritative positions compared to students. Earlier studies show that students on their first clinical placements may be uncomfortable asking questions and being assertive because they feel RNs are the 'big bosses', holding positions of authority and thus students are unwilling to question them (Rogan et al 2006). As a result, students wait to be told what to do by the RN who may then decide the students lack initiative. Students may be reluctant to speak in groups of native speakers, as required in clinical handover sessions and debriefing sessions because they are embarrassed about their accent or lack of language proficiency (Sanner et al 2002). In assessing students, facilitators need to be aware of factors that contribute to students' apparent lack of engagement with the learning environment.

Comments about personality, evident in this study may relate to the intuitive judgement raised by Jette et al (2007). If facilitators are comfortable with students who are 'happy, enthusiastic and outgoing' then they may be likely to judge the student as competent. 
Whilst there were only a few personality type comments on the assessment forms, the extent to which these influenced facilitators' overall judgements is unclear. General comments about 'good' students do indicate, however, that personality traits such as happy, enthusiastic and outgoing are important. As diverse cultural norms of behaviour related to learning style and relative positions of authority as well as students' level of anxiety can contribute mismatching expectations on clinical (Rogan et al 2006), one way of addressing the role of intuition is to make explicit to both facilitators and students the kinds of attributes assessors look for when assessing students. This would facilitate discussions among faculty, hospitals and students about the cultural expectations of clinical placement, make the expected cultural norms familiar to students from diverse cultural backgrounds and enable facilitators to become aware of their cultural biases to take these into account when assessing students. Discussions about the complexities of cultural expectations in an increasingly culturally and linguistically diverse workforce would also be promoted.

\section{CONCLUSION}

This study is early research into clinical facilitators' expectations of ESL students' clinical communication performance. However, it does indicate that facilitators do indeed assess students' language performance and have clear ideas about students' communication and behaviour.

Much of the responsibility for preparation and success on clinical placement has so far been placed on students. There is, however, a need for facilitators and universities to make more explicit the expectations of clinical placement. Facilitators' expectations may be influenced by their cultural background as well as the culture of the workplace. Students may not always be aware of the expected ways of behaving or the possible effects their behaviour may have on the way they are assessed. Making these expectations transparent to students may alleviate some of the students' anxieties associated with clinical placement. The findings from this study have been used in the development of online materials and workshops with first year students to help prepare them for clinical placement.

There is also a need for improved preparation of facilitators working with ESL students, particularly regarding language assessment to enable facilitators to develop confidence in assessing ESL students. These findings are a useful way to begin such education as they offer insights into the kind of expectations facilitators have of students on clinical placement and how these issues might be made explicit and negotiated with students.

\section{REFERENCES}

Australian Nursing and Midwifery Council (ANMC), 2006 National competency standards for the registered nurse $4^{\text {th }}$ ed Dickson ACT ANMC

Bosher, S., Smalkoski, K ., 2002. From needs analysis to curriculum development: 
designing a course in health-care communication for immigrant students in the USA. English for Specific Purposes 21 (1), 59-79

Boughton, M.A., Halliday, L.E., Brown, L., 2010. A tailored programme of support for culturally and linguistically diverse (CALD) nursing students in a graduate entry Masters of Nursing course: A qualitative evaluation of outcomes. Nurse Education in Practice 10 (6), 355-360

Brown, J. F., 2008. Developing an English-as-a-second-language program for foreignborn nursing students at an historically black university in the Unites States. Journal of Transcultural Nursing 19, 184-191

Calman, L., Watson R., Norman, I., Redfern, S., Murrells, T., 2002. Assessing practice of student nurses: methods, preparation of assessors and student views. Journal of Advanced Nursing 38 (5), 515-523

Choi, L.L.S., 2005. Literature review: Issues surrounding Education of English-as-asecond language (ESL) nursing students. Journal of Transcultural Nursing 16 (3), 263-268

Chur-Hansen, A., Vernon-Roberts, J., 1998. Clinical teachers' perceptions of medical students’ English language proficiency. Medical Education 32, 351-356

Clynes, M.P., Raftery, S.E.C., 2008. Feedback: An essential element of student learning in clinical practice. Nurse Education in Practice 8 (6), 405-411

Dolan, G., 2003. Assessing student nurse competency: will we ever get it right? Journal of Clinical Nursing 12 (1), 132-141

Fothergill Bourbonnais, F., Langford S., Giannantonio, L., 2008. Development of a clinical evaluation tool for baccalaureate nursing students. Nurse Education in Practice 8 ( ), 62-71

Gilchrist, K.L., Rector C., 2007. Can you keep them? Strategies to attract and retain nursing students from diverse populations: Best practices in nursing education. Journal of Transcultural Nursing 18 (3), 277-285

Gonda, J., Hussin, V., Blackman, I., Gaston, J., 1995. Migrant nurses: their unique value. In Gray G, Pratt R (eds) Issues in Australian Nursing 4. Churchill Livingstone, Melbourne, p 129-144

Guhde J., 2003. English as a second language (ESL) nursing students: Strategies for building verbal and written language skills. Journal of Cultural Diversity 10 (4), 113-117 
Gunn-Lewis, J., Smith, L., 1999. Developing communication skills for clinical practice: from Chinese doctor to New Zealand nurse. Research and Development in Higher Education 22 available from http://www.herdsa.org.au/branches/vic/Cornerstones/authorframeset.html

Hussin, V., 1999. From classroom to clinical: towards a model of learning support for NESB students in clinical placements. Research and Development in Higher Education 22 available from http://www.herdsa.org.au/branches/vic/Cornerstones/authorframeset.html

Jette, D.U., Bertoni, A., Coots, R., Johnson, H., McLaughlin, C., Weisbach. C., 2007. Clinical instructors' perceptions of behaviors that comprise entry-level clinical performance in physical therapist students: A qualitative study. Physical Therapy $87(7), 833-843$

McCarthy, B., Murphy, S., 2008. Assessing undergraduate nursing students in clinical practice: Do preceptors use assessment strategies? Nurse Education Today 28 ( 3), $301-313$

Malthus, C., Holmes, J., Major, G., 2005. Completing the circle: Research-based classroom practice with EAL nursing students. New Zealand Studies in Applied Linguistics, 11 (1), 65-89

Malu, K ., Figlear, M., 1998. Enhancing the language development of immigrant EAL nursing students: A case study with recommendations for action. Nurse Educator $23(2), 43-46$

Melia, K., 1987. Learning and Working: The Occupational Socialization of Nurses. Tavistock, London

Nursing and Midwifery Council 2010 Standards for pre-registration nursing education http://standards.nmc-uk.org/PreRegNursing/non-statutory/Pages/supporting-advice.aspx

Omeri, A., Malcolm, P., Ahern, M., Wellington, B., 2003. Meeting the challenges of cultural diversity in the academic setting. Nurse Education in Practice 3 (1), 5-22

Rogan, F., San Miguel, C., Brown, D., Kilstoff, K., 2006. "You find yourself". Perceptions of nursing students from non-English speaking backgrounds of the effect of an intensive language support program on their oral communication skills. Contemporary Nurse 23 (1), 72-86

Sanner, S., Wilson, A.H., Samson, L.F., 2002. The experience of international nursing students in a baccalaureate nursing program. Journal of Professional Nursing, 18, 206-213 
San Miguel, C., Rogan, R., Brown, D., Kilstoff, K., 2006. Clinically Speaking: A communication skills program for students from non-English speaking backgrounds. Nurse Education in Practice 6 (5), 268-274

San Miguel, C., Rogan, F., 2009. A good beginning: The long-term effects of a clinical communication programme. Contemporary Nurse 33 (2), 179-190

Seibold, C., Rolls, C., Campbell, M., 2007. Nurses on the move: Evaluation of a programme to assist international students undertaking an accelerated Bachelor of Nursing programme Contemporary Nurse 25 (1), 63-71

Thorne, S., Kirkham, S., MacDonald-Emes, J., 1997. Interpretive description: a noncategorical qualitative alternative for developing nursing knowledge Research in Nursing \& Health 20(2), 169-177 